Full citation:

Praskova, A., Creed, P. A., \& Hood M. (2013). Facilitating engagement in new career goals: The moderating effects of personal resources and career actions. International Journal for Educational and Vocational Guidance, 13, 115-134. doi:10.1007/s10775-013-9242-2

Facilitating Engagement in New Career Goals: The Moderating Effects of Personal Resources and Career Actions

Anna Praskova, Peter A. Creed, Michelle Hood

School of Applied Psychology and Griffith Health Institute

Griffith University, Australia

Contact Anna Praskova, PhD candidate

School of Applied Psychology

Mailbox 58

Griffith University

Gold Coast, Qld, Australia 4222

a.praskova@griffith.edu.au

Prof Peter Creed p.creed@griffith.edu.au

Dr Michelle Hood m.hood@griffith.edu.au 


\begin{abstract}
Goal engagement in young adults is variable. We recruited university students to test whether general personal characteristics (educational ability, core self-evaluations, and well-being; Study $1, N=195$ ) and career adaptive variables (career confidence, exploration, and planning; Study 2, $N=152$ ) facilitated career goal engagement. Goal engagement was associated positively with goal disengagement in Study 1. Moderating effects showed that the positive relationship between engagement and disengagement was stronger when core selfevaluations and well-being (satisfaction) were high, and when career confidence, exploration, and planning were high. Results are discussed in the context of transitions and promoting adaptable career goals.
\end{abstract}

Keywords: goal disengagement; goal engagement; goal adjustment; self-evaluations; career planning; career exploration; career self-efficacy 


\section{Facilitating Engagement in New Career Goals: The Moderating Effects of Personal Resources and Career Actions}

Goals give direction, structure, and meaning to people's lives and contribute to well-being (Shulman \& Nurmi, 2010a; Wrosch, Scheier, Carver, \& Schulz, 2003). Commitment to and persistence in pursuing self- and other-set goals, including confidence about overcoming adversity and being able to marshal the resources needed to attain the goals, are important aspects of adaptive self-regulation (Bandura \& Locke, 2003; Carver \& Scheier, 1998). "Giving up" has been treated as an undesirable response (i.e., viewed as failure), equated with "helplessness", and thought to lead to increased stress and reduced well-being (Miller \& Wrosch, 2007; Wrosch, Scheier, Carver et al., 2003). However, Wrosch, Scheier, Carver et al. (2003) argued that giving up is a necessary, "natural and indispensable aspect of personal development and effective self-regulation" (p.2). While people make important choices about which goals to strive for, they also make decisions about which goals cannot be achieved and should be adjusted or abandoned. They abandon goals because of inherited constraints, limited biological resources, limited life span, and socio-structural and age-normative constraints (Wrosch, Scheier, Carver et al., 2003).

In the transition period between finishing education and commencing work, young adults are attracted to and set many life goals, but when valued choices face obstacles and become unattainable to them, their goal pursuit can lead to disappointment and reduced well-being (Shulman \& Nurmi, 2010b). In such circumstances, young people have to draw on their selfregulatory and coping responses to manage their challenges. The main developmental tasks for young adults are selecting a career and making plans for a future life and family (Shulman \& Nurmi, 2010a). These tasks of decision-making and planning invariably result in individuals letting go of many existing goals (e.g., hobbies) and investing in more futurefocused domains (e.g., education; Shulman \& Nurmi, 2010b). Thus, one important way to 
manage obstacles is to disengage from previously held goals that become unachievable and engage in new ones (Wrosch, Scheier, Miller, Schulz, \& Carver, 2003). Engaging in new goals is especially important as this is related to life purpose and well-being (Shulman \& Nurmi, 2010a). However, individuals differ in their reactions to unattainable goals, with some finding it easier than others to abandon existing goals and/or set new ones (Wrosch \& Scheier, 2003). This has implications for well-being and actions (Heckhausen, Wrosch, \& Schulz, 2010), but there is very limited literature on what facilitates engaging in new goals when unattainable goals have been put on hold or abandoned.

We report two studies that assessed the contribution of various personal attributes and resources to increasing goal engagement when disengagement from unattainable career goals has occurred in young adults. In Study 1, we tested the effects of personal characteristics, namely ability (educational achievement), well-being (satisfaction and affective well-being), and self-evaluations (core self-evaluations). In Study 2, we focused on career-related facilitators, namely career self-efficacy, career planning, and career exploration.

\section{Goal Adjustment}

People use self-regulation to diminish discrepancies between their present and ideal situations; that is, they act to increase/reduce effort associated with achieving their goals, act to adjust their goals by lowering/raising or abandoning them, or combine changes in effort and goal adjustment strategies (Carver \& Scheier, 1998). Self-regulation strategies in situations where goals are perceived to have become unattainable involve the capacity to disengage from unachievable goals and the capacity to engage in alternative, meaningful ones (Wrosch, Scheier, Miller, et al., 2003). Successful goal disengagement involves withdrawing effort and commitment to the unattainable goal so that repeated failures are prevented, negative states relieved, and resources freed to be used for alternative actions (Wrosch, Miller, Scheier, \& Brun de Pontet, 2007). Individuals also need to be able to engage in 
alternative, meaningful goals, involving the ability to identify, commit, and initiate activities directed towards alternate goal attainment.

Savickas' (1999) theory of career adaptation acknowledged that individuals need to possess skills to cope with unpredictable adjustments that are prompted by changes in the environment. University students, for example, have to set alternative educational and career goals if their original ones are perceived as unattainable. Robitschek and Cook (1999) argued that students' recognition of barriers to their career path was a necessary first step in order to engage in new goal-directed behaviours, and stated that the effective use of self-regulatory strategies was the main contributing factor to successful career development. The level of career development varies substantially among young adults, as does the effective use of selfregulatory strategies (Robitschek \& Cook, 2009). As young people often fine-tune or redefine their occupational plans, the processes around these adjustments are seen as adaptive responses that can contribute to better outcomes (Savickas, 1999). In other words, when young people disengage from occupational goals that are blocked or perceived as unattainable and engage in more realistic alternatives, they exercise self-regulation and open themselves up to experiencing better career and general outcomes (Carver \& Scheier, 1998). However, despite goal adjustment being an important self-regulatory strategy generally, and especially important in the career area where many options are explored, considered, and then abandoned, limited research has examined the construct as a self-regulatory response in a career context.

\section{Goal Adjustment, Well-being, and Behaviour}

Goal disengagement and goal engagement are somewhat trait-like and largely independent of one another (Wrosch, Scheier, Miller et al., 2003). Thus, each can contribute independently to well-being and lead to behaviour change. Goal adjustment has been associated with better well-being when coping with illness (Neter, Litvak, \& Miller, 2009; 
Schroevers, Kraaij, \& Garnefski, 2008) or when caring for a family member with illness (Wrosch, Amir, \& Miller, 2011), although in some situations, goal disengagement or goal engagement alone is associated with better well-being (Wrosch, Scheier, Miller et al., 2003). Specific to the career area, positive coping is associated with more career planning and less emotional distress (Lightfoot \& Healy, 2001), reflective coping strategies are associated with more career exploration (Robitschek \& Cook, 2009), goal disengagement is associated with more career planning and exploration, and engagement is associated with more career exploration (Creed \& Blume, 2013).

\section{Goal Engagement}

People who fail to disengage from out-of-reach goals can baulk at or be prevented from engaging with new goals and opportunities, which can result in reduced life progress and poorer well-being. On the other hand, those who can disengage from unattainable goals and engage in new ones benefit from better well-being (Carver \& Scheier, 1998). Goal disengagement and goal engagement are independent constructs, although they can interact with one another to deliver positive outcomes. For example, the ability to engage in alternative goals moderates the relationships between goal disengagement and well-being (Wrosch et al., 2007; Wrosch, Scheier, Miller et al., 2003) and behaviours (Creed \& Blume, 2013). Students who were low on both disengagement and engagement reported the highest distress and engaged in the least career planning and exploration (Creed \& Blume, 2013). This moderation effect, however, has not always been found. Wrosch, Scheier, Miller et al. (2003) found that goal engagement facilitated higher levels of well-being for older, but not for younger adults, and that the effect was evident for perceived stress and self-mastery, but not for other markers of well-being. They concluded that other factors might play an important role in the adaptive self-regulation of goals.

\section{Facilitating Goal Engagement}


Wrosch, Scheier, Miller et al. (2003) argued that having viable alternative goals is a crucial component of the goal adjustment process and that goal engagement can be facilitated by personal and contextual variables. Consistent with this, Duke, Leventhal, Brownlee, and Leventhal (2002) found that unwell older adults were more likely to replace lost activities when new ones were available and that the uptake of these activities was facilitated by support and encouragement from others. On the downside, O'Connor and Forgan (2007) found that pressure from others to do well and to meet expectations was negatively associated with goal engagement. Also, there is a growing consensus that person-based factors (e.g., personality, coping strategies) influence the way that people manage goal-directed progress (Tosevski, Milovancevic, \& Gajic, 2010; Wrosch \& Scheier, 2003), and that adaptive personal resources might facilitate the identification of a new goal (Shulman \& Nurmi, 2010b; Wrosch \& Miller, 2009). In the career area, Heckhausen et al. (2010) also argued that when career paths become unstable, people have to rely on their personal and social capital.

The role of affect is also widely supported (Austin \& Vancouver, 1996). Wrosch, Scheier, Miller et al. (2003) proposed that better well-being might drive people's goal disengagement and engagement, rather than be an outcome of goal adjustment as shown by previous studies (Wrosch, Scheier, Miller et al., 2003). Consistent with this, positive affect was associated with increased goal engagement in cancer patients, while negative affect and worrying were associated with less (Schroevers et al., 2008). Greater perceived stress in adults was also associated with reduced goal engagement (Wrosch et al., 2007). We identified no studies that specifically tested general personal resources (e.g., personality, ability, well-being,) or context-specific resources (e.g., self-efficacy, career-related strategies) as facilitators of goal engagement.

\section{Current Studies}

Study 1 tested the moderating effects of ability, well-being, and core self-evaluations on 
the relationship between goal disengagement and goal engagement. We expected that higher ability (educational achievement), better well-being (affective well-being, satisfaction with life), and more personal resources (core self-evaluations) would facilitate goal engagement. We tested these hypotheses on a sample of young adults and used adjustment to careerrelated goals as the context for goal disengagement and engagement. In Study 2, we tested the moderating effects of three context-specific variables, namely career self-efficacy, career planning, and exploration, on the relationship between goal disengagement and engagement on a second sample of young adults.

\section{Study 1}

\section{Method}

Participants. Participants were 195 first-year Australian university students (73\% female), with a mean age of 18.95 years $(S D=1.35$; range 17-22). Mean achievement level in high school was $2.92(S D=.69$; "What grade did you typically receive in Year 12?", with a 5-point response format ranging from 1 very limited achievement to 5 very high achievement.

Instruments. Students completed scales assessing goal adjustment, core self-evaluations, and well-being. All scales used a 6-point Likert-like response format (range $=1$ strongly disagree to 6 strongly agree). Higher scores indicate higher construct levels. The first section of the questionnaire asked the students to reflect on the university courses they had applied for in the previous year, and the jobs they had hoped these courses would lead to (ideal goals). They were asked to write down their responses. They were then asked to think about and write down the career compromises they made in the transition to university, such as the career they now think they might have, the salary they might start with/end up with, and where they might work (modified goals). This set the context for answering questions about goal adjustment. 
Goal adjustment. We used the 10-item Goal Adjustment Scale (Wrosch, Scheier, Miller et al., 2003), with minor adjustments (e.g., "goal" was changed to "career goal"), to assess goal disengagement and goal engagement. The 4-item disengagement subscale (e.g., "I found it difficult to stop trying to achieve this career goal") and the 6-item engagement subscale (e.g., "I thought about other new careers to pursue") have demonstrated sound psychometric properties with college students, with alphas above .80 , confirmation of a 2 -factor structure, and support for construct validity (Wrosch, Scheier, Miller et al., 2003; Miller \& Wrosch, 2007). Alphas for our sample were .75 (disengagement) and .94 (engagement).

Core self-evaluations. We used the 12-item Core Self-evaluations Scale (Judge, Erez, Bono, \& Thoresen, 2003), which taps four core personality traits: self-esteem, generalised self-efficacy, neuroticism, and locus of control (e.g., "I am confident I get the success I deserve in life"). The scale has been tested on college students and adults, and found to reflect a single factor, to have good reliability (alpha $>.80$, test-retest reliability $=.81$ ), and support for convergent and divergent validity (Judge et al., 2003). Alpha with our sample was .84 .

Well-being. Subjective well-being was assessed using the 5-item Satisfaction with Life Scale (Diener, Emmons, Larsen, \& Griffin, 1985). Sample item was, "I'm satisfied with my life". Good reliability has been reported with college students (alpha $=.87,2$-month testretest reliability $=.82$ ), and validity supported by finding expected correlations with other scales (Diener et al., 1985). Alpha for our sample was .87. Affective well-being was assessed using the 5-item Well-being Index (World Health Organization, 1998), which assesses recent positive mood, vitality, and general interest. Sample item was, "I have felt cheerful and in good spirits". The Index has been used with adolescents and adults and compares favourably with other well-being measures; alphas above .80 have been reported (De Wit, DelemarreVan De Waal, Pouwer, Gemke, \& Snoek, 2007). Alpha in our sample was .87. 
Procedure. The study was approved by our university ethics committee. Students were recruited towards the end of their first semester at university via their course web page and from announcements in class. They completed the paper-and-pencil questionnaire in their own time and returned it to the researchers. They received course credit and had their name placed in a prize draw to win a $\$ 50$ shopping voucher for participating.

\section{Results}

We used hierarchical regression analyses to assess if ability (educational achievement), personal strengths (core self-evaluations), and well-being (life satisfaction, affective wellbeing) facilitated the relationship between goal disengagement and goal engagement. Age and gender were not associated with goal engagement, and were not included as covariates (see Table 1for bivariate correlations). In all analyses, goal engagement was the outcome variable, goal disengagement was included at Step 1, the moderator variable at Step 2, and a goal disengagement $\mathrm{x}$ moderator interaction term at Step 3. The interaction terms were created using products of centred terms (Aiken \& West, 1991). Significant interaction effects were graphed using Dawson and Richter's (2006) computational tool, which generated simple regression lines based on values of the moderator $1 S D$ above and below the mean.

When academic achievement was the moderator, disengagement at Step 1 accounted for $16.8 \%$ of the variance in goal engagement, $F(1,193)=39.11, p<.001$, and academic achievement at Step 2, $F(1,192)=2.57, p=.11$, and the interaction term at Step 3, $F(1,191)$ $=1.01, p=.32$, were not significant (see Table 2). With core self-evaluation as the moderator, core self-evaluation at Step 2 was not significant, $F(1,192)=.44, p=.51$, but the interaction term at Step 3 was, $F(1,191)=5.18, p=.02$, adding $2 \%$ of variance. With life satisfaction as the moderator, only the interaction term at Step 3 was significant, $F(1,191)=$ 4.72, $p=.03$, adding $2 \%$. With affective well-being as the moderator, neither Step $2, F(1$, $192)=.36, p=.36$, nor Step $3, F(1,191)=.43, p=.51$, was significant. For the significant 
interactions between goal disengagement and core self-evaluations and life satisfaction, goal engagement was low when goal disengagement was low, and increased as goal disengagement increased. However, that increase was greater when core self-evaluation and well-being were high (see Figure 1).

\section{Discussion}

Study 1 assessed the relationship between career goal disengagement and career goal engagement, and tested the moderating effects of three general personal characteristics (educational achievement, well-being, and core self-evaluations) on that relationship. First, we found a moderate relationship between goal disengagement and goal engagement, which is consistent with the notion that the two constructs are largely independent (Wrosch, Scheier, Miller et al., 2003). Second, goal engagement was not associated directly with educational achievement, well-being, or core self-evaluations. Previous results here have been inconsistent, with some studies finding direct associations (e.g., Duke et al., 2002; Wrosch et al., 2007; Wrosch et al., 2011) and others finding goal engagement not directly related to well-being or personality (Creed \& Blume, 2013; Wrosch, Scheier, Miller et al., 2003). The interaction effects found in our study shed light on these mixed results.

We found that higher life satisfaction and stronger core self-evaluations facilitated goal engagement in modified or new career goals. As goal disengagement increased, so did goal engagement; however, goal engagement was greater for those who judged their life to be more satisfactory and for those with stronger core self-evaluations. Thus, perceiving both one's life and one's self in more positive ways facilitates actions towards finding a new goal. These facilitative effects are consistent with the proposition by Wrosch, Scheier, Miller et al. (2003) that higher levels of well-being could be a driving force behind goal adjustment, rather than the other way around, although longitudinal data are required to confirm this. They are also consistent with the general proposition that adaptive personality resources, such 
as viewing one's self and the world more positively, facilitates better coping, and in this case, increases goal engagement (Wrosch \& Miller, 2009).

However, we did not find facilitative effects for educational achievement or affective well-being on goal engagement. Previous studies found that positive affect was related to higher goal engagement, while negative affect (e.g., stress, worrying) was linked with less (Schroevers et al., 2008; Wrosch et al., 2007). However, again, other studies did not find this (Creed \& Blume, 2013; Wrosch, Scheier, Miller et al., 2003), suggesting, for example, that context may play a role in the well-being/goal engagement relationship. In our study, we used two general measures of well-being, when a context-specific well-being measure might have been more appropriate. Second, our results for educational achievement are inconsistent with the proposition by Heckhausen et al. (2010) that social capital (e.g., educational attainment) is a driving force underpinning goal-striving processes. However, our study did not assess the social capital construct fully, and sampling all high ability young adults (university students) might have reduced any association with this variable. This proposition needs to be assessed on a more diverse sample where educational achievement is more variable.

As we were assessing young adults in transition and asking them to consider their career goal adjustment, other, more career specific, adaptability characteristics, might play an important role. This is in line with expectancy-based theories, which suggest that behaviour is best predicted when the specificity of the expectancy matches that of the behaviour (Rasmussen, Wrosch, Scheier, \& Carver, 2006), and consistent with Savickas' (1999) proposition that career adaptability incorporates effective planning, decision making, confidence/problem solving, and exploration.

\section{Study 2}

Career self-efficacy is the judgement of one's ability to perform career-related behaviours associated with career choice (Anderson \& Betz, 2001). Rasmussen et al. (2006) argued that 
when people settle on a goal, and this goal attainment is disrupted, they suspend their behaviours and effort, step back from the situation, and re-evaluate their circumstances. This involves re-assessing one's level of efficacy to reach the goal (e.g., confidence regarding alternative paths or goals). Rasmussen et al. suggested that people with more favourable concepts of the self, the world, and the future (i.e., more confident and optimistic) should benefit by being more able to engage in new activities. Consistent with this, they found that optimism was associated with goal engagement in university students. Similarly, Aspinwall and Richter (1999) showed that university students with more favourable beliefs (greater optimism and greater sense of control) more easily disengaged from unsolvable tasks and engaged in new ones, and allocated more effort to these new tasks than students with less favourable beliefs. Creed and Hood (in press) found a positive association between selfefficacy and goal engagement. They also found that higher levels of efficacy facilitated less career distress and more career planning. We extended this work to test the facilitative effect of career-related self-efficacy on goal engagement.

Action behaviours are implemented to assist in meeting individuals' career goals (Phillips \& Blustein, 1994); thus, should be relevant to engagement in new goals. Career planning, which is related positively to career success (Hall \& Chandler, 2005), involves organising information one has about career choice and preparing a course of action, and might include setting sub-goals, identifying strategies, and setting tasks and deadlines necessary to progress one's career (Zikic \& Klehe, 2006). Career exploration, which is especially important when careers are unstable or the person is in transition (Hall \& Chandler, 2005), involves gathering information related to career progress. It includes exploring one's own values, interests, and experiences, and examining the external environment, such as education and training options, occupations, and specific employers (Zikic \& Klehe, 2006). Individuals with more favourable self- and world-views are better able to moderate their effort and actions, and exercise 
personal active control over events, for example, by exploring alternatives and planning (Aspinwall \& Richter, 1999) and initiating activities directed towards a new goal (e.g., investment of effort; Wrosch \& Scheier, 2003). Thus, people who have an easier time identifying new goals and initiating actions (e.g., planning, exploration) should be more able to replace the goals that have become unattainable (Wrosch et al., 2011). Goal engagement was associated with career-related exploration (Creed \& Blume, 2013) and career planning (Creed \& Hood, in press). In addition, Robitschek and Cook (1999) showed that career planning and exploration were closely linked to effective use of self-regulatory strategies. However, we found no study that tested the facilitative effect of these career action behaviours on goal adjustment.

In summary, Study 2 tested the moderating effects of three career-specific adaptive characteristics (career self-efficacy, career planning, and career exploration) on the goal engagement capacity of young adults. We expected that higher career self-efficacy and more career planning and exploration would facilitate goal engagement.

\section{Method}

Participants. Participants were a second sample of 152 first-year Australian university students; $73 \%$ female), who were surveyed in their first semester at university (2 surveys were discarded due to extensive missing data). They had a mean age of 19.36 years $(S D=$ 1.93; range 17-25) and a mean high school academic achievement level of $3.92(S D=.65)$.

Instruments. Participants completed scales assessing goal adjustment, career efficacy, career planning and exploration. All scales used a 6-point response format ranging from 1 strongly disagree to 6 strongly agree, with higher scores indicating more of a particular construct.

Goal adjustment. This was the same 10-item Goal Adjustment Scale (Wrosch, Scheier, Miller et al., 2003) used in Study 1. The internal reliability coefficients with this sample were 
.73 (goal disengagement) and .93 (goal engagement).

Career planning. This was measured using the 8 -item career thinking and planning subscale of the Career Salience Scale (Greenhaus, 1971). Students indicated their agreement with statements such as, "I enjoy thinking about and making plans for my future career". Reliability coefficients for the full scale range from .70 to .80 , and validity has been supported by testing associations with other career variables (e.g., perceived prestige of chosen occupation; Greenhaus, 1971; Zikic \& Klehe, 2006). Alpha for this sample was .74.

Career exploration. Stumpf, Colarelli, and Hartman's (1983) Career Exploration Survey was used to assess environmental exploration (6 items; e.g., "To what extent, in the past three months have you been investigating career possibilities") and self-exploration (5 items; e.g., "To what extent, in the past three months have you reflected on how your past integrates with your future life and career"). Alpha coefficients above .80 have been reported, and validity has been assessed by testing factor structure and correlations with other career variables (Creed, Fallon, \& Hood, 2009). Alphas for our sample were .88 (environmental) and .85 (self).

Career self-efficacy. We used the 12 items from the Career Decision Making Selfefficacy Scale (Betz, Klein, \& Taylor, 1996), selected by Fouad, Smith, and Enochs (1997) to reflect the construct assessed by the full scale (Betz \& Luzzo, 1996). A sample item was, "How confident are you that you could: ...decide what you value most in an occupation". The full scale, which measures confidence for undertaking activities associated with career decision making, has been validated using university students. Fouad et al. reported alpha coefficient of .79 , tested the factor structure, and assessed correlations with other career variables. Alpha for our sample was .89.

Procedure. University ethics approval was obtained for Study 2, and students were recruited in the same manner as for Study 1. 


\section{Results}

We used similar hierarchical regression analyses to Study 1 to test if career planning, exploration, and self-efficacy facilitated engaging in career-related goals. Gender, but not age or academic achievement, was associated with goal engagement, and was included as a control variable. See Table 3. In all analyses, goal engagement was the outcome variable, gender was entered at Step 1, goal disengagement was included at Step 2, the moderator variable was included at Step 3, and the goal disengagement $\mathrm{x}$ moderator interaction was added at Step 4. See Table 4 for summary data.

Gender at Step 1 accounted for $4.3 \%$ of variance in goal engagement, $F(1,150)=6.77, p$ $=.01$. Disengagement at Step 2 was not significant, $F(1,149)=2.91, p=.09$. Career planning as the moderator at Step 3 accounted for $2.9 \%$ variance, $F(1,148)=4.69, p=.03$, and the interaction of career planning $\mathrm{x}$ disengagement at Step 4 accounted for another $4.8 \%$, $F(1,147)=8.16, p=.005$. Career self-exploration at Step 3 accounted for $2.4 \%, F(1,148)=$ 3.87, $p=.05$, and the interaction term at Step 4 added an extra $4.1 \%, F(1,147)=6.90, p=$ .01 . Environmental exploration at Step 3 accounted for $3.2 \%, F(1,148)=.5 .15, p=.02$, and the interaction term at Step 4 added 2.7\%, $F(1,147)=4.58, p=.03$. Last, career self-efficacy accounted for $4.9 \%$ at Step $3, F(1,148)=4.76, p=.03$, and the interaction term contributed $5.4 \%$ at Step $4, F(1,147)=9.23, p=.003$.

When graphed, the significant interaction effects showed that goal engagement was low at all levels of goal disengagement when career planning, career self-exploration, career environment exploration, and career self-efficacy were low. However, goal engagement increased as goal disengagement increased when planning, self-exploration, environment exploration, and self-efficacy were high (see Figure 2).

\section{Discussion}

Study 2 tested the facilitative effects of career-specific adaptive characteristics (career 
planning, exploration, and self-efficacy) on the tendency to engage in modified or new career goals during goal adjustment. Career planning, environmental exploration, and self-efficacy were significantly, positively associated with goal engagement; self-exploration was not. These results are in line with the findings of others (Creed \& Blume, 2013; Creed \& Hood, in press; Wrosch et al., 2011). In this sample, goal disengagement was not significantly associated with goal engagement. However, the relationship was moderated by career selfefficacy, planning, and exploration. As goal disengagement increased, so did goal engagement, although only for students with higher levels of career self-efficacy, and those with higher engagement in career planning and career exploration of the self and the environment. For students lower on career self-efficacy, planning, and exploration, goal engagement was low at all levels of goal disengagement.

These anticipated results suggest that perceived confidence about one's ability to perform career-related behaviours, and the actual engagement in career behaviours in the face of a career challenge and disengagement are important context-specific factors that facilitate engagement in modified or new career goals. This supports the proposition that people with more optimistic beliefs about their career activities are more adaptable in modifying their behaviours, actions, and efforts in the face of unattainable goals (Aspinwall \& Richter, 1999). The study also supported propositions that people who initiate actions in the face of goal disengagement, such as exploring career alternatives, analysing career information, and planning for a future course of action (i.e., future career goal pursuit) more easily replace an unachievable goal (Wrosch et al., 2011).

\section{General Discussion}

The current studies responded to the call to examine the reactions to and management of specific (i.e., career) unattainable goals (Wrosch, Scheier, Miller et al., 2003). The studies contribute to a better understanding of the complexities surrounding career goal adjustment in 
young adults when they have to move on from goals that they decide are unachievable. Our studies were the first to attempt to explain why goal adjustment has not consistently been associated with outcomes in the past (Wrosch, Scheier, Miller et al., 2003), or why goal disengagement and goal engagement were not always strongly associated with one another. While factors facilitating disengagement have been reviewed elsewhere (Wrosch, Scheier, Carver et al., 2003), the literature and research on factors that facilitate goal engagement are scarce. We have demonstrated that third variables can play an important part in the goal adjustment process, and conclude that the relationship between goal disengagement and goal engagement is more complex than first thought.

The engagement of young people in new career goals can be energised by having a positive view of the self and life in general, and is facilitated by their judgement or confidence that they can perform context-specific actions and engage in the specific activities directed towards exploring and planning for alternatives. This is an important contribution to the career development literature that promotes adaptable personal characteristics in young people, such as planful competence, the realisation of one's potential, positive orientation, adjustment to new career environments (e.g., university, revised career goals), and exploration of career alternatives (Skorikov, 2007), and adds to the goal adjustment literature generally (Wrosch, Scheier, Miller et al., 2003). In sum, our study adds to the literature on how individual characteristics influence management of both predictable and unpredictable challenges to their career paths and to their future preparation for work; that is, adds to the literature on career adaptability (Savickas, 1997).

We hope our studies will motivate future research to test the moderating effects of other variables in career goal adjustment, and adjustment in other domains of people's lives. In the career domain, for example, future research needs to investigate the role of third variables external to the young person that could affect the relationship between goal disengagement 
and goal engagement. These could include both facilitative and limiting effects, such as the effects of family and social support, availability of alternative goals, demands and expectations of others, or barriers associated with pursuing a chosen career goal. These variables are all relevant to young people, who, on the one hand, develop their own selfviews and are active agents in determining the direction of their future life, but who, on the other, also need to take into account the expectations and actions of others and the limitations imposed by external constraints (Shulman \& Nurmi, 2010b). As goal engagement is considered to follow goal disengagement (Wrosch, Scheier, Carver et al., 2003), future studies need to assess changes over time now that cross-sectional correlates have been demonstrated, and test more heterogeneous samples in order to generalize the results beyond this sample of first-year university students. Last, as career development occurs across the lifespan, future studies might focus on how career goal adjustment develops and is managed over time, considering both personal resources and contextual demands.

\section{Conclusion}

As goal engagement was facilitated by having more positive self-views, being more satisfied with life (Study 1), having higher levels of self-efficacy, and engaging in more planning and exploration (Study 2), these studies have implications for the development of healthy self-regulation and goal management strategies in young adults. As many career counsellors see successful career preparation as crucial to young people's future employability, occupational success, and life satisfaction, interventions could incorporate teaching general and career goal adjustment strategies, along with focusing on young people's self-concept and confidence, and the value of managing their well-being and engaging in proactive exploration and planning. As goal adjustment is an important adaptive skill that increasingly develops in adolescence (Carver \& Scheier, 1998), promotion of this skill could be integrated into early educational programs in order to develop more positive, 
resilient, and better adjusted young people who are better prepared for upheavals in their future occupational life.

\section{References}

Aiken, L. S., \& West, S. G. (1991). Multiple regression: Testing and interpreting interactions. Newbury Park, CA: Sage.

Anderson, S. L., \& Betz, N. E. (2001). Sources of social self-efficacy expectations: Their measurement and relation to career development. Journal of Vocational Behavior, 58, 98117. doi:10.1006/jvbe. 2000.1753

Aspinwall, L. G., \& Richter, L. (1999). Optimism and self-mastery predict more rapid disengagement from unsolvable tasks in the presence of alternatives. Motivation and Emotion, 23, 221-245. doi:10.1023/A:1021367331817

Austin, J. T., \& Vancouver, J. B. (1996). Goal constructs in psychology: Structure, process, and content. Psychological Bulletin, 120, 338-375. doi:10.1037/0033-2909.120.3.338

Bandura, A., \& Locke, E. A. (2003). Negative self-efficacy and goal effects revisited. Journal of Applied Psychology, 88, 87-99. doi:10.1037/0021-9010.88.1.87

Betz, N. E., Klein, K. L., \& Taylor, K. M. (1996). Evaluation of a short form of the CareerDecision-Making Self-Efficacy Scale. Journal of Career Assessment, 4, 47-57. doi:10.1177/106907279600400103

Betz, N. E., \& Luzzo, D. A. (1996). Career assessment and the Career Decision-Making SelfEfficacy Scale. Journal of Career Assessment, 4, 413-428. doi:10.1177/106907279600400405

Carver, C. S. \& Scheier, M. F. (1998). On the self-regulation of behavior. Cambridge, MA: Cambridge University Press.

Creed, P. A., \& Blume, K. (2013). Compromise, well-being, and action behaviours in young adults in career transition. Journal of Career Assessment, 21, 3-19. 
doi:10.1177/1069072712453830

Creed, P. A., Fallon, T., \& Hood, M. (2009). The relationship between career adaptability, person and situation variables, and concerns in young adults. Journal of Vocational Behavior, 74, 219-229. doi:10.1016/j.jvb.2008.12.004

Creed, P. A., \& Hood, M. (in press). Disengaging from unattainable career goals and reengaging in more achievable ones. Journal of Career Development.

Dawson, J. F., \& Richter, A. W. (2006). Probing three-way interactions in moderated multiple regression: Development and application of a slope difference test. Journal of Applied Psychology, 91, 917-926. doi:10.1016/S0021-9010(06)61901-8

De Wit, M., Delemarre-Van De Waal, H., Pouwer, F., Gemke, R. J., \& Snoek, F. J. (2007). Validation of the WHO-5 Well-being Index in adolescents with Type 1 diabetes. Diabetes Care, 30, 2003-2006. doi:10.2337/dc07-0447

Diener, E., Emmons, R. A., Larsen, R. J., \& Griffin, S. (1985). The Satisfaction with Life Scale. Journal of Personality Assessment, 49, 71-75. doi:10.1207/s15327752jpa4901_13

Duke, J., Leventhal, H., Brownlee, S., \& Leventhal, E. A. (2002). Giving up and replacing activities in response to illness. Journal of Gerontology: Psychological Sciences, 57B, 367-376. doi:10.1093/geronb/57.4.P367

Fouad, N. A., Smith, P. L., \& Enochs, L. (1997). Reliability and validity evidence for the Middle School Self-efficacy Scale. Measurement and Evaluation in Counseling and Development, 39, 17-31. Retrieved from http://search.proquest.com/

Greenhaus, J. (1971). An investigation of the role of career salience in vocational behaviour. Journal of Vocational Behavior, 1, 209-216. doi:10.1016/0001-8791(71)90022-4

Hall, D. T., \& Chandler, D. E. (2005). Psychological success: When the career is a calling. Journal of Organizational Behavior, 26, 155-176. doi: 10.1002/job.301

Heckhausen, J., Wrosch, C., \& Schulz, R. (2010). A motivational theory of life-span 
development. Psychological Review, 117, 32-60. doi: 10.1037/a0017668

Judge, T. A., Erez, A., Bono, J. E., \& Thoresen, C. J. (2003). The Core Self-evaluations Scale. Personnel Psychology, 56, 303-331. doi:10.1111/j.1744-6570.2003.tb00152.x

Lightfoot, M., \& Healy, C. (2001). Career development, coping, and emotional distress in youth living with HIV. Journal of Counselling Psychology, 48, 484-489. doi:10.1037/0022-0167.48.4.484

Miller, G. E., \& Wrosch, C. (2007). You've gotta know when to fold 'em: Goal disengagement and systematic inflammation in adolescence. Psychological Science, 18, 773-777. doi:10.1111/j.1467-9280.2007.01977.x

Neter, E., A. Litvak, A., \& Miller, A. (2009). Goal disengagement and goal re-engagement among multiple sclerosis patients: Relationship to well-being and illness representation. Psychology and Health, 24, 175-186. doi:10.1080/08870440701668665

O’Connor, R. C., \& Forgan, G. (2007). Suicidal thinking and perfectionism: The role of goal adjustment and behavioural inhibition/activation systems (BIS/BAS). Journal of RationalEmotive \& Cognitive-Behavior Therapy, 25, 321-341. doi:10.1007/s10942-007-0057-2

Phillips, S. D., \& Blustein, D. L. (1994). Readiness for career choices: Planning, exploring, and deciding. The Career Development Quarterly, 43, 63-71. doi:10.1002/j.21610045.1994.tb00847.x

Rasmussen, H. N., Wrosch, C., Scheier, M. F., \& Carver, C. S. (2006). Self-regulation processes and health: The importance of optimism and goal adjustment. Journal of Personality, 74, 1721-1748. doi:10.1111/j.1467-6494.2006.00426.x

Robitschek, C., \& Cook, S. W. (1999). The influence of personal growth initiative and coping styles on career exploration and vocational identity. Journal of Vocational Behavior, 54, 127-141. doi:10.1006/jvbe.1998.1650

Savickas, M. L. (1997). Career adaptability. The Career Development Quarterly, 45, 247- 
259. doi:10.1002/j.2161-0045.1997.tb00469.x

Savickas, M. L. (1999). The transition from school to work. The Career Development Quarterly, 47, 326-336. doi:10.1002/j.2161-0045.1999.tb00741.x

Schroevers, M., Kraaij, V., \& Garnefski, N. (2008). How do cancer patients manage unattainable personal goals and regulate their emotions? British Journal of Health Psychology, 13, 551-562. doi:10.1348/135910707X241497

Shulman, S., \& Nurmi, J. (2010a). Dynamics of goal pursuit and personality make-up among emerging adults. In S. Shulman \& J. Nurmi (Eds.), The role of goals in navigating individual lives during emerging adulthood (pp. 57-70). San Francisco, CA: Wiley.

Shulman, S., \& Nurmi, J.-E. (2010b). Understanding emerging adulthood from a goal-setting perspective. In S. Shulman \& J.-E. Nurmi (Eds.), The role of goals in navigating individual lives during emerging adulthood (pp. 1-11). San Francisco, CA: Wiley.

Skorikov, V. (2007). Continuity in adolescent career preparation and its effects on adjustment. Journal of Vocational Behavior, 70, 8-24. doi:10.1016/j.jvb.2006.04.007

Stumpf, S. A., Colarelli, S. M., \& Hartman, K. (1983). Development of the Career Exploration Survey (CES). Journal of Vocational Behavior, 22, 191-226. doi:10.1016/0001-8791(83)90028-3

Tosevski, D. L., Milovancevic, M. P., \& Gajic, S. D. (2010). Personality and psychopathology of university students. Current Opinion in Psychiatry, 23, 48-52. doi:10.1097/YCO.0b01e328333d625

World Health Organization: Collaborating Centre in Mental Health. WHO (Five) Well-being Index (1998 version). Psychiatric Research Unit, Frederiksborg General Hospital, DK: Hillerød. Retrieved from http://www.who-5.org/

Wrosch, C., Amir, E., \& Miller, G. E. (2011). Goal adjustment capacities, coping, and subjective well-being. Journal of Personality and Social Psychology, 100, 934-946. 
doi:10.1037/a0022873

Wrosch, C., \& Miller, G. E. (2009). Depressive symptoms can be useful: Self-regulatory and emotional benefits of dysphoric mood in adolescence. Journal of Personality and Social Psychology, 96, 1181-1190. doi:10.1037/a0015172

Wrosch, C., Miller, G. E., Scheier, M. F., \& Brun de Pontet, S. (2007). Giving up on unattainable goals: Benefits for health? Personality and Social Psychology Bulletin, 33, 251-265. doi:10.1177/0146167206294905

Wrosch, C., \& Scheier, M. F. (2003). Personality and quality of life: The importance of optimism and goal adjustment. Quality of Life Research, 12, 59-72. doi:10.1023/A:1023529606137

Wrosch, C., Scheier, M. F., Miller, G. E., Schulz, R. \& Carver, C. S. (2003). Adaptive selfregulation of unattainable goals: Goal disengagement, goal reengagement, and subjective well-being. Personality and Social Psychology Bulletin, 29, 1494-1508.

doi:10.1177/0146167203256921

Wrosch, C., Scheier, M. F., Carver, C. S., \& Schulz, R. (2003). The importance of goal disengagement in adaptive self-regulation: When giving up is beneficial. Self and Identity, 2, 1-20. doi:10.1080/15298860309021

Zikic, J., \& Klehe, U.-C. (2006). Job loss as a blessing in disguise: The role of career exploration and career planning in predicting reemployment quality. Journal of Vocational Behavior, 69, 391-409. doi:10.1016/j.jvb.2006.05.007 
Table 1

Bivariate Correlations Among All Study 1 Variables; $N=195$

\begin{tabular}{|c|c|c|c|c|c|c|c|c|c|c|}
\hline Variable & $M$ & $S D$ & 1 & 2 & 3 & 4 & 5 & 6 & 7 & 8 \\
\hline 1. Goal disengagement & 12.92 & 4.36 & - & $.41 * * *$ & .07 & .10 & -.01 & -.06 & .07 & .00 \\
\hline 2. Goal engagement & 21.97 & 7.47 & & . & .13 & .08 & .01 & .01 & .08 & -.02 \\
\hline 3. Academic achievement & 2.92 & .69 & & & - & $-.15^{*}$ & -.12 & -.12 & $.20 * *$ & -.12 \\
\hline 4. Core self-evaluation & 48.95 & 8.26 & & & & - & $.66^{* * *}$ & $.63 * * *$ & .11 & -.12 \\
\hline 5. Life satisfaction & 20.75 & 4.96 & & & & & - & $.73 * * *$ & .05 & -.06 \\
\hline 6. Affective well-being & 21.15 & 4.68 & & & & & & - & .05 & -.06 \\
\hline 7. Age & 18.95 & 1.35 & & & & & & & - & $-.18^{*}$ \\
\hline 8. Gender & - & - & & & & & & & & - \\
\hline
\end{tabular}

$* p<.05, * * p<.01, * * * p<.001$ 
Table 2

Summary of Hierarchical Multiple Regression Analyses Predicting Goal Engagement, with Moderators of Academic Achievement, Core Self Evaluation, Subjective Well-being, and Affective Well-being $(N=195)$

\begin{tabular}{|c|c|c|c|c|c|c|c|c|c|c|c|c|}
\hline \multirow[b]{3}{*}{ Variables } & \multicolumn{12}{|c|}{ Moderators } \\
\hline & \multicolumn{3}{|c|}{ Academic Achievement } & \multicolumn{3}{|c|}{ Core Self-evaluation } & \multicolumn{3}{|c|}{ Life Satisfaction } & \multicolumn{3}{|c|}{ Affective Well-being } \\
\hline & $B$ & $S E(B)$ & $\beta$ & $B$ & $S E(B)$ & $\beta$ & $B$ & $S E(B)$ & $\beta$ & $B$ & $S E(B)$ & $\beta$ \\
\hline \multicolumn{13}{|l|}{ Step 1} \\
\hline Goal disengagement & .70 & .11 & $.41 * * *$ & .70 & .11 & $.41 * * *$ & .70 & .11 & $.41 * * *$ & .70 & .11 & $.41 * * *$ \\
\hline \multicolumn{13}{|l|}{ Step 2} \\
\hline Goal disengagement & .69 & .11 & $.40 * * *$ & .70 & .11 & $.41 * * *$ & .70 & .11 & $.41 * * *$ & .70 & .11 & $.41 * * *$ \\
\hline Moderator & 1.14 & .71 & .11 & .04 & .06 & .04 & .03 & .10 & .02 & .06 & .11 & .04 \\
\hline \multicolumn{13}{|l|}{ Step 3} \\
\hline Goal disengagement & .66 & .12 & $.39 * * *$ & .68 & .11 & $.40 * * *$ & .66 & .11 & $.39 * * *$ & .70 & .11 & $.41 * * *$ \\
\hline Moderator & 1.19 & .71 & .11 & .05 & .06 & .05 & .02 & .10 & .01 & .07 & .11 & .04 \\
\hline Goal disengagement $\mathrm{x}$ Moderator & -.48 & .48 & -.07 & 1.11 & .49 & $.15^{*}$ & .95 & .44 & $.14 *$ & .29 & .44 & .04 \\
\hline
\end{tabular}



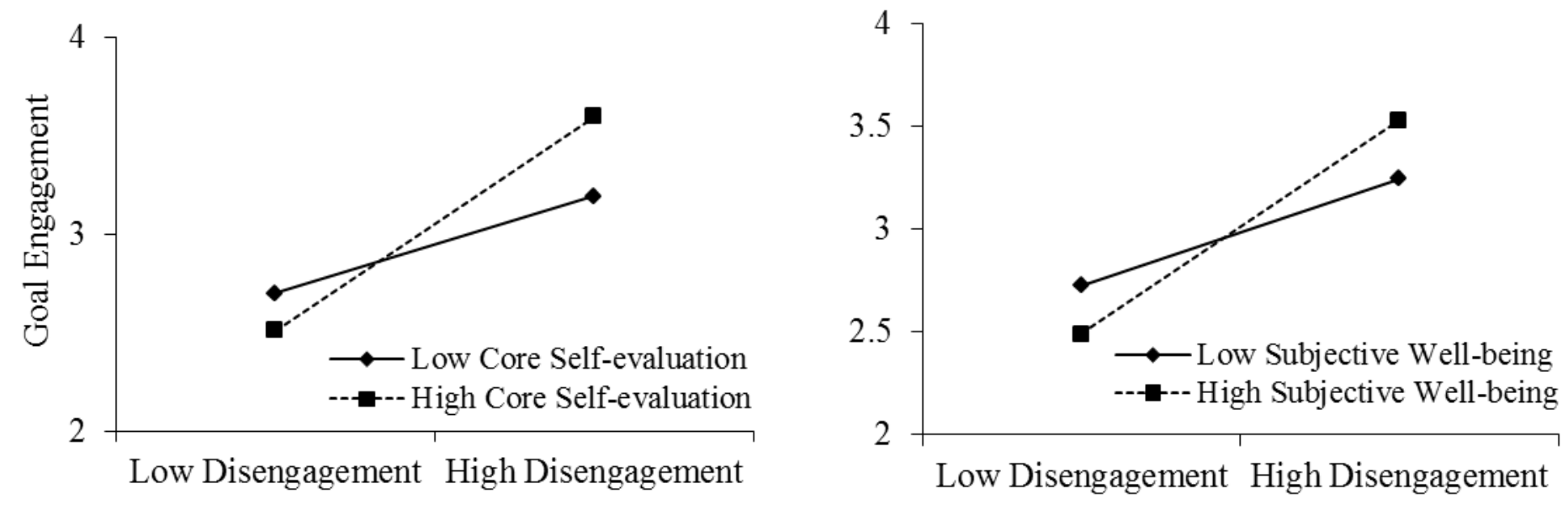

Figure 1. (a) Core self-evaluations and (b) subjective well-being (life satisfaction) moderating the relationship between goal disengagement and goal engagement 
Table 3

Bivariate Correlations Among All Study 2 Variables; $N=152$

\begin{tabular}{|c|c|c|c|c|c|c|c|c|c|c|c|}
\hline Variable & $M$ & $S D$ & 1 & 2 & 3 & 4 & 5 & 6 & 7 & 8 & 9 \\
\hline 1. Goal disengagement & 15.06 & 4.05 & - & .15 & -.06 & $-.16^{*}$ & -.08 & .09 & -.14 & .05 & .09 \\
\hline 2. Goal engagement & 28.39 & 5.60 & & - & $.20 *$ & .14 & $.16^{*}$ & $.21 *$ & -.03 & -.04 & $.21 *$ \\
\hline 3. Career plannning & 34.34 & 5.80 & & & - & $.48 * * *$ & $.41 * * *$ & $.44 * * *$ & -.10 & .05 & $.20 *$ \\
\hline 4. Self-exploration & 19.75 & 4.82 & & & & - & $.45 * * *$ & $.26 * *$ & -.01 & .03 & .02 \\
\hline 5. Environment exploration & 22.84 & 5.57 & & & & & - & $.29 * * *$ & .00 & -.03 & -.02 \\
\hline 6. Career self-efficacy & 51.55 & 8.98 & & & & & & - & $-.20 *$ & -.08 & .14 \\
\hline 7. Academic achievement & 3.92 & .65 & & & & & & & - & .14 & -.03 \\
\hline 8. Age & 19.36 & 1.93 & & & & & & & & - & .04 \\
\hline 9. Gender & - & - & & & & & & & & & - \\
\hline
\end{tabular}

${ }^{*} p<.05, * * p<.01, * * * p<.001$ 
Table 4

Summary of Hierarchical Multiple Regression Analyses Predicting Goal Engagement, with Moderators of Career Planning, Career Self-exploration, Career Environmental Exploration, and Career Self-efficacy $(N=152)$

\begin{tabular}{|c|c|c|c|c|c|c|c|c|c|c|c|c|}
\hline \multirow[b]{3}{*}{ Variables } & \multicolumn{12}{|c|}{ Moderators } \\
\hline & \multicolumn{3}{|c|}{ Planning } & \multicolumn{3}{|c|}{ Self-exploration } & \multicolumn{3}{|c|}{ Environment Exploration } & \multicolumn{3}{|c|}{ Self-efficacy } \\
\hline & $B$ & $S E(B)$ & $\beta$ & $B$ & $S E(B)$ & $\beta$ & $B$ & $S E(B)$ & $\beta$ & $B$ & $S E(B)$ & $\beta$ \\
\hline \multicolumn{13}{|l|}{$\overline{\text { Step } 1}$} \\
\hline Gender & 2.61 & 1.00 & $.21 * *$ & 2.61 & 1.00 & $.21 * *$ & 2.61 & 1.00 & $.21 * *$ & 2.61 & 1.00 & $.21 * *$ \\
\hline \multicolumn{13}{|l|}{ Step 2} \\
\hline Gender & 2.45 & 1.00 & $.20 *$ & 2.45 & 1.00 & $.20 *$ & 2.45 & 1.00 & $.20 *$ & 2.45 & 1.00 & $.20^{*}$ \\
\hline Goal disengagement & .19 & .11 & .14 & .19 & .11 & .14 & .19 & .11 & .14 & .19 & .11 & .14 \\
\hline \multicolumn{13}{|l|}{ Step 3} \\
\hline Gender & 2.00 & 1.01 & .16 & 2.38 & .99 & $.19 *$ & 2.47 & .99 & $.20 *$ & 2.16 & 1.00 & $.17 *$ \\
\hline Goal disengagement & .21 & .11 & .15 & .22 & .11 & $.16^{*}$ & .21 & .11 & .15 & .17 & .11 & .12 \\
\hline Moderator & .17 & .08 & .17 & .18 & .09 & $.16^{*}$ & .18 & .08 & $.18^{*}$ & .11 & .05 & $.17 *$ \\
\hline \multicolumn{13}{|l|}{ Step 4} \\
\hline Gender & 1.66 & .99 & .13 & 2.32 & .97 & $.19^{*}$ & 2.34 & .98 & $.19 *$ & 1.90 & .98 & .15 \\
\hline Goal disengagement & .16 & .11 & .12 & .28 & .11 & $.20 *$ & .24 & .11 & $.17 *$ & .22 & .11 & $.16^{*}$ \\
\hline Moderator & .22 & .08 & .22 & .19 & .09 & .16 & .17 & .08 & $.17 *$ & .15 & .05 & $.24 * *$ \\
\hline Goal disengagement $\mathrm{x}$ Moderator & 1.18 & .41 & $.23 * *$ & 1.03 & .39 & $.21 * *$ & .90 & .42 & $.17 *$ & 1.21 & .40 & $.24 * *$ \\
\hline $\begin{array}{l}\text { Note: } \text { For career planning as moder } \\
R^{2} \text { at Step } 4=.14\left(R^{2}{ }_{A d j}=.12\right) \text {; for } \\
.09\left(R_{A d j}^{2}=.07\right), R^{2} \text { at Step } 4=.13 \\
\left(R_{A d j}^{2}=.05\right), R^{2} \text { at Step } 3=.09\left(R^{2}\right. \\
\text { at Step } 2=.06\left(R_{A d j}^{2}=.05\right), R^{2} \text { at St }\end{array}$ & $R^{2}$ at & Step & $\begin{array}{l}=.04 \\
\text { ation, } R \\
\text { career }\end{array}$ & $d j=.04$ & $R^{2}$ & $\begin{array}{l}\text { Step } 2 \\
R_{\text {Adj }}^{2}=\end{array}$ & $\begin{array}{l}.06\left(R^{2}\right. \\
94), R^{2}\end{array}$ & $j=.0$ & $\begin{array}{l}), R^{2} \text { at } \\
=.06 \\
4\left(R^{2}\right.\end{array}$ & $\begin{array}{l}\mathrm{p} 3=. \\
\mathrm{dj}=.05\end{array}$ & $\begin{array}{l}09(R \\
), R^{2} \\
2 \text { at } \mathrm{St} \\
\left(R^{2}{ }_{A d j}\right.\end{array}$ & $\begin{array}{l}\text { Adj }=.07 \\
\text { Step } 3 \\
\text { p } 2=.\end{array}$ \\
\hline
\end{tabular}



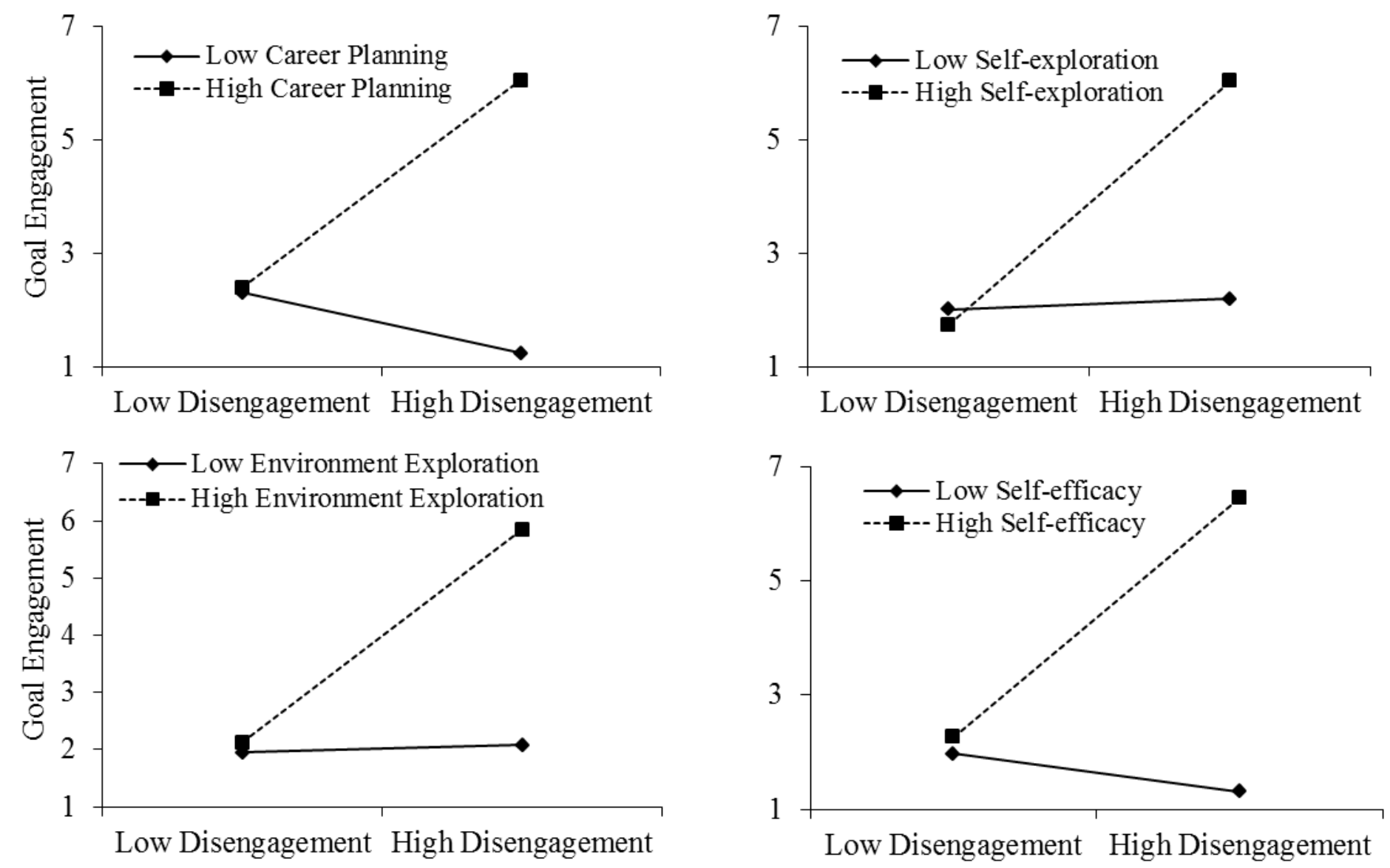

Figure 2. (a) Career planning, (b) self-exploration, (c) environment exploration, and (d) self-efficacy moderating the relationship between goal disengagement and goal engagement 